\title{
Questão Agrária e Projeto Nacional: notas para um debate $^{*}$
}

\author{
Fernando dos Santos Sampaio*
}

\section{Resumo}

O presente artigo tem como objetivo fazer alguns apontamentos sobre as interpretações da agricultura brasileira que tem sido frequentes na Geografia Agrária. Busca-se levantar alguns pontos que são de fundamental importância para a interpretação do campo brasileiro, propondo uma reflexão que possa dar embasamento a um Projeto Nacional. Ao se falar em um Projeto Nacional é preciso destacar como a agricultura se insere nele e também pensar em como a Geografia, ou mais especificamente a Geografia Agrária, pode contribuir para se entender melhor a agricultura brasileira.

Palavras-chave: Geografia Agrária; Projeto Nacional; Agricultura.

Agrarian Question and National Project: notes for a debate

\begin{abstract}
This article aims to make some notes on the interpretations of Brazilian agriculture that has been common in Agricultural Geography. The aim is to raise some points that are of fundamental importance for the interpretation of the Brazilian countryside,
\end{abstract}

* O artigo foi escrito tomando por base a transcrição da exposição feita na XXXV - Semana da Geografia UFSC (SEMAGEO) Florianópolis em 07/10/2014. Agradeço a Helton Rogério da Rosa pela transcrição da gravação da mesa redonda.

* Professor do curso de Geografia da Universidade Estadual do Oeste do Paraná, campus Francisco Beltrão (fssampa@gmail.com).

Geosul, Florianópolis, v. 29, ESPECIAL, p 39-56, jul./dez. 2014 
SAMPAIO, F. dos S. Questão Agrária e Projeto Nacional: notas para...

offering a reflection that can give basis to a National Project. When we speak of a National Project is necessary to highlight as agriculture falls on it and also think about how geography or more specifically the Agricultural Geography can contribute to better understand the Brazilian agriculture.

Key words: Agricultural Geography; National Project; Agricultural.

\section{A importância da Geografia}

A Geografia é uma ciência de síntese. O fato de ser uma ciência de síntese na qual se trabalha a Natureza e a Sociedade, tanto em suas relações entre si quanto nas suas especificidades, permite o uso de dois grandes paradigmas: Geossistemas e Formação Sócio-espacial ${ }^{1}$. Nesse sentido, a agricultura dentre todos os setores econômicos é o que vai mostrar mais claramente, ou talvez mais didaticamente, essa relação entre sociedade e natureza e a importância que o estudo da Geografia tem para poder entende-la em suas especificidades, mas também buscando um entendimento de totalidade.

Atualmente alguns estudos da Geografia Agrária tem perdido esse caráter de totalidade, se preocupando muito mais com a "porteira para dentro" do que com o entendimento de relações mais amplas da agricultura. E hoje em dia não dá mais para se falar apenas na agricultura da "porteira para dentro". Não que os estudos de caso que tem sido feitos na Geografia Agrária não tenham importância, mas para se entender algo de um ponto de vista mais amplo ou para se pensar num projeto nacional é necessário entender a relação da agropecuária com os demais setores produtivos.

A maior parte da agricultura brasileira já está integrada a um mercado que vai desde os agro-serviços, ao processamento

${ }^{1}$ A importância desses dois paradigmas tem sido trabalhada por Armen Mamigonian, para maiores detalhes ver Mamigonian, (2005). 
SAMPAIO, F. dos S. Questão Agrária e Projeto Nacional: notas para...

agroindustrial, a toda uma rede de financiamentos da agricultura, sua inserção com as grandes cadeias de produção, com as grandes cadeias de distribuição. E a Geografia Agrária $^{2}$ muitas vezes tem se negado a estudar o papel da grande produção agrícola nos processos de desenvolvimento nacional e da organização do território. Em geral quando se fala da grande produção apenas se busca ressaltar seus aspectos negativos, da exploração e da concentração, como se fossem característicos apenas da agricultura e não do modo de produção capitalista como um todo. A dicotomia do Bem contra o Mal vai se tornando presente e obscurecendo a interpretação e o entendimento.

Esses estudos esquecem da Formação Social que é importantíssima, daí muitas vezes apresentar o Brasil e Bolívia como sendo a mesma coisa, a mesma formação social. Os movimentos dos cocaleiros, os movimentos indígenas e camponeses na Bolívia (e em outros países da América do Sul) tem enorme importância, mas não dá para atribuir a mesma importância a esses movimentos no Brasil, como já foi apresentado por estudiosos do tema é um equívoco trabalhar com a categoria de campesinato para analisar o atual meio rural no Brasil ${ }^{3}$. E mais ainda, de entender esse "campesinato" como tendo um potencial revolucionário.

${ }^{2}$ Em geral, nos programas da disciplina de Geografia Agrária no Brasil e nos dois principais eventos de Geografia Agrária, o, Encontro Nacional de Geografia Agrária (ENGA) e o Simpósio Internacional de Geografia Agrária (SINGA), se vê muito mais estudos de caso no qual se entende a agricultura muitas vezes apenas da "porteira para dentro" e não se dá muito espaço para se falar das relações mais amplas.

${ }^{3}$ Entre os autores que consideram equivocadas o uso do conceito de campesinato no Brasil vale destacar Germer (2012) e Navarro (2010). Os dois autores, de matrizes teóricas diferentes, apresentam os argumentos de porque consideram equivocado o uso do conceito de camponês para analisar o meio rural brasileiro na atualidade. Atualmente o conceito mais consagrado para análise da "pequena agricultura" tem sido o de agricultor familiar. 
SAMPAIO, F. dos S. Questão Agrária e Projeto Nacional: notas para...

\section{Trabalhadores assalariados, agricultores e luta de classes}

Em geral os pesquisadores e estudantes de Geografia tem uma característica marcante de querer uma mudança social, de ter uma preocupação social, muitas vezes sendo mais à esquerda ou se entender como esquerda. Assim muitas vezes acaba se confundindo o movimento da pequena burguesia, um movimento que prega a existência da pequena propriedade como se ela fosse algo revolucionário, esquecendo-se, principalmente dos anos 1990 em diante, do "trabalhador" na agricultura. A acelerada industrialização do Brasil no século XX fez com que o movimento de trabalhadores ${ }^{4}$ nas cidades tivesse grande importância nas lutas sociais, os trabalhadores nas indústrias de transformação agrícola, nas indústrias de máquinas para a agricultura (internalizada desde os anos 1970), os trabalhadores temporários no corte da cana, na colheita da laranja, do café e de outras culturas que popularmente ficou conhecido como os "boias-frias". Reduzir todos esses trabalhadores à categoria de camponeses acaba gerando equívocos que prejudicam a elaboração de estratégias de lutas contra o capital, ou mesmo em outra perspectiva, a elaboração de políticas públicas que beneficiem esses trabalhadores.

Dificilmente tem aparecido na atualidade textos ou trabalhos que falem do trabalhador rural, do proletariado na agricultura e quando se fala no proletário, muitas vezes ele é entendido como aquele que não teve acesso à propriedade, por isso ele é um proletariado, mas que o desejo dele, o seu "profundo desejo" é de ser um pequeno proprietário. Daí não se falar mais em políticas ou não se falar mais em estratégias de luta para um proletariado na

${ }^{4}$ A partir de um amplo trabalho empírico e inúmeras entrevistas Broietti (2004) mostra que os trabalhadores rurais do norte do Paraná não mais se consideram agricultores sem-terra, mas sim trabalhadores assalariados cuja vida se dá na cidade não havendo mais o interesse da volta para o campo. A região onde se fez a pesquisa é significativa em relação ao número de "boias-frias". Na geografia é um dos poucos trabalhos que trata do assunto nesta perspectiva. 
SAMPAIO, F. dos S. Questão Agrária e Projeto Nacional: notas para...

agricultura, mas sim em reforma agrária, pois essa resolveria todos os problemas, desde o cortador de cana até o integrado na cadeia de frangos, passando pelos trabalhadores do comércio nas cidades.

Porque que se perdeu o viés de se analisar a totalidade? Porque que se perdeu uma capacidade de identificação de classes, identificação de estratégia de classe ou de interesses de classes. É importante saber se esse sujeito que estão chamando de camponês, ou agricultor familiar, ou de pequeno agricultor, é aliado do proletariado numa luta ou não? Dos trabalhadores em geral, ele é um aliado com potencial em determinados momentos ou não? Essa pergunta se quer está sendo colocada.

Mas por que não se faz mais uma análise nessa perspectiva? Uma das causas foi a perda de força do marxismo nos anos 1990 por conta daquilo que chamamos de contrarrevolução Neoliberal, que é algo de direita, mas conquistou muitos corações da esquerda e tirou o foco de interpretação na luta de classes. Falar em luta de classes passou a ser considerado algo de mau gosto, em alguns casos, um termo proibido.

O marxismo nos anos 1990 não perde força porque teoricamente é mais fraco do que as novas interpretações que aparecem, em muitos casos ele é colocado na ilegalidade. No lesteeuropeu depois daquela contrarrevolução Neoliberal extremamente violenta ${ }^{5}$, boa parte dos partidos comunistas foram colocados na ilegalidade.

A implantação do neoliberalismo não foi algo sutil, não foi um debate de ideias que colocou o marxismo numa situação defensiva, foi algo extremamente violento que chegou a eliminação física em alguns lugares, como a gente bem sabe. No Brasil criouse um ambiente bastante hostil para os marxistas, inclusive na universidade. E não era apenas ser hostilizado pela direita, mas os grupos mais à esquerda, daquela esquerda que não tinha nada a ver com o "Socialismo Real", também hostilizavam os marxistas,

${ }^{5}$ Para detalhes do impacto do neoliberalismo na Rússia ver Batchikov, Glasev e Kara-Murza (2007). 
SAMPAIO, F. dos S. Questão Agrária e Projeto Nacional: notas para...

porque eram totalitários, porque eram culpados pelas mortes durante a Guerra Fria, porque os marxistas tinham uma visão totalizadora que não incluía o pequeno, a cultura, os desejos... enfim a pluralidade que os neoliberais tanto prezam.

Esse colocar "de escanteio o marxismo" no ambiente das discussões, acabou fazendo com que o debate da questão agrária ficasse centralizado apenas nas questões sociais, nas relações do bem-estar social, se submetendo a aquilo que a direita quer discutir. A esquerda deixa de falar em classes sociais, a Geografia Agrária deixa de falar em classes sociais e se cria então aquela diferença que não é mais a diferença entre os proletários e burgueses, não se entende mais o fazendeiro (ou o "dono do agronegócio", das empresas agrícolas) como um membro da burguesia, mas se entende que ele é um sujeito diferente da burguesia em geral, que possui uma especificidade. E essa especificidade, segundo esta interpretação, se baseia na luta do grande contra o pequeno. Então a base da discussão torna-se a dicotomia entre o grande capital, representado por aquilo então que se chama de agronegócio e o pequeno capital, representado por aquilo que vai ser chamada "agricultura familiar", como se fossem frações diferentes da burguesia, como se um fosse o representante daquilo que é o atraso (o capitalismo) e o outro representante do futuro, porque no futuro todos seremos proprietários, desde que pequenos proprietários.

Ora, cria-se aí nessa interpretação algumas falsas dicotomias $^{6}$, uma delas a ideia do bem e do mal, o grande é o mal e o pequeno é o bem, o grande é o moderno e o pequeno arcaico, defender o moderno é mau, e assim justifica-se as críticas a modernização da agricultura.

Então, quando se analisa boa parte da produção na Geografia Agrária dos anos 1990 e 2000, se percebe essa crítica a modernização da agricultura, que a modernização da agricultura concentrou renda, que a modernização da agricultura fez com que

${ }^{6}$ Para maiores detalhes sobre as dicotomias nas interpretações sobre a questão agrária no Brasil ver Gonçalves (2004). 
SAMPAIO, F. dos S. Questão Agrária e Projeto Nacional: notas para...

o pequeno perdesse sua terra, provocou êxodo rural, porque desempregou no meio rural e tudo mais. Ora, se a gente for fazer uma análise da modernização da agricultura pelo viés marxista, tomando por pressuposto que vivemos numa sociedade capitalista, onde predomina a produção de mercadorias, onde a organização social é voltada à acumulação de capital, temos que lembrar que nesse contexto a agricultura não produz alimentos, a agricultura produz capital. Dentro dessa lógica, da existência de uma relação dialética entre o avanço das forças produtivas e das relações de produção, muitas vezes esses estudos na Geografia Agrária acabam se preocupando muito mais com as relações de produção sem considerar os avanços das forças produtivas e o papel progressista que esta tem na transformação social ${ }^{7}$.

A agricultura brasileira após a modernização se modifica bastante, ela se torna uma agricultura altamente competitiva internacionalmente, ela vai estar integrada a um ramo maior de acumulação de capital, não dá mais para estudar a agricultura por ela mesma ${ }^{8}$. Da mesma forma que não dá para analisar os impactos da modernização da agricultura apenas olhando para a agricultura. Quando se compara os preços dos alimentos, como feito na figura a seguir, é possível perceber que a modernização da agricultura diminuiu bruscamente o gasto com alimentos, hoje nós temos alimentos muito mais baratos do que nos anos setenta e oitenta do século XX. Esse alimento barato é fruto da agricultura que se transformou numa agricultura altamente moderna e produtiva em quase todos os produtos.

${ }^{7}$ Essa relação é uma das categorias centrais do marxismo, uma boa apresentação da discussão encontra-se em Germer (2009).

${ }^{8}$ Obviamente isso não é uma novidade, mas muitas das interpretações sobre o campo brasileiro na geografia tem deixado de lado as profundas transformações ocorridas na agricultura nos últimos 20 anos. Um bom panorama das principais mudanças pode ser encontrado em Buainain et all (2013). 
SAMPAIO, F. dos S. Questão Agrária e Projeto Nacional: notas para...

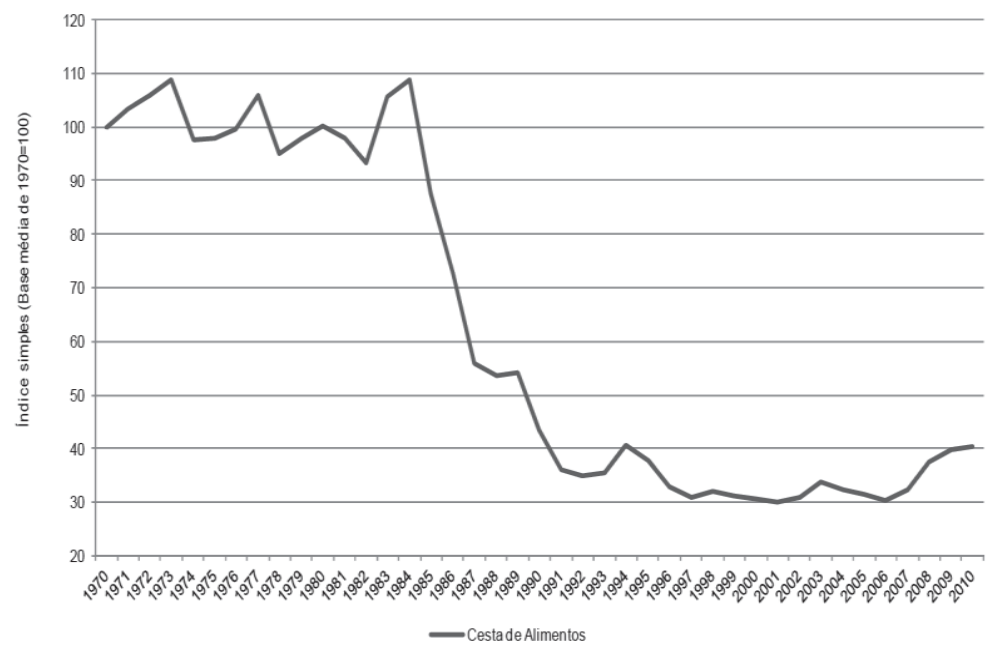

Figura 1 - Evolução dos İndices de Preços de Alimentos ao Consumidor Paulistano, Médias Anuais para a Cesta de Mercado, São Paulo, 1970-2010.

Fonte: Dados da pesquisa.

Fonte: Gonçalves, 2012, p. 88

Outro ponto que ressaltamos é o pressuposto marxista que a realidade é fruto como síntese de múltiplas determinações, por isso então não se pode falar apenas nas relações culturais, não dá para falar como tem sido comum que o pequeno proprietário resiste ao capitalismo porque ele ainda apanha o limão no pé. Isso não é resistir ao capitalismo. Porque ele tem amor a terra? Isso não é resistir ao capitalismo. O que é resistir ao capitalismo? A História é rica em exemplos de resistência camponesa ao capitalismo, o Eric Wolf no livro "Guerras Camponesas do Século XX", que por mais que se discorde de algumas de suas interpretações sobre qual classe dirige tal ou qual revolução, ele mostra a importância dos camponeses em revoluções no mundo inteiro.

${ }^{9}$ Entre os casos apresentados por Wolf (1984) são os do México, Rússia, China, Vietnã, Argélia e Cuba. 
SAMPAIO, F. dos S. Questão Agrária e Projeto Nacional: notas para...

Mas falar em resistência ao capitalismo tem dois sentidos, um no sentido de sua superação, a resistência dos trabalhadores ao capital e outro no sentido de preservar as relações anteriores ao capitalismo. Então a resistência ao capitalismo não é apenas no sentido de querer algo novo, querer algo superior, mas também é na manutenção daquilo que é arcaico, que é pré-capitalista. Marx e Engels (1975) mostraram essa concepção muito bem no Manifesto Comunista quando fazem a crítica ao que chamam de "Socialismo feudal". Mostram que esse "socialismo feudal" não é um socialismo que entende as contradições do capitalismo e propõe algo novo, algo que incorpore os avanços do capitalismo e chegue a uma sociedade superior, mas é apenas um socialismo que não quer que se manifeste as características do desenvolvimento do capitalismo, que destrói a concorrência, a pequena produção, a pequena propriedade. Querem de volta aquilo que é idílico, aquela relação do homem com a natureza, que de fato nunca existiu. Eles querem a volta daquela bela ordem feudal, por isso Marx e Engels os consideravam profundamente reacionários.

Atualmente se vê muita gente fazendo a defesa de uma interpretação equivocada de que "capitalismo é igual desigualdade social”, não que não seja, mas não é a única forma de desigualdade, não é essa a característica fundamental do capitalismo, a desigualdade social existiu em outros modos de produção, no escravismo, no feudalismo, no modo de produção asiático. No capitalismo há uma especificidade dessa desigualdade social e é entendendo essa especificidade que se pode propor uma nova sociedade que supere o capitalismo, não a volta ao que era antes da sua fase monopólica, não a volta ao momento do capitalismo concorrencial. Então, falar em políticas públicas para que o capitalismo consiga ser o capitalismo que foi outrora, que foi em momentos do seu nascimento, é pura enganação, pois isso não é mais possível.

\section{Agricultura e produção agroalimentar}

Quando se fala da produção de alimentos é necessário entender o sistema agroalimentar por inteiro. Por exemplo, aquela 
SAMPAIO, F. dos S. Questão Agrária e Projeto Nacional: notas para...

imagem que aparece como viral em páginas da internet - "a produção de alimentos no Brasil é feita majoritariamente por camponeses"10 - é fruto de uma interpretação equivocada do Ministério do Desenvolvimento Agrário em um anexo do censo agropecuário do IBGE de 2006/2007, separando um volume específico sobre a agricultura familiar. O que o MDA expõe é que a produção de alimentos é feita majoritariamente pela agricultura familiar e que a produção feita pelo agronegócio é fundamentalmente voltada ao mercado externo, algo que já se demonstrou não ser tão verdadeiro como apresentado pelo $\mathrm{MDA}^{11}$. Para aprofundar o equívoco, no viral apresentado, toma-se como sinônimos a "agricultura familiar" e a "agricultura camponesa" e se apresenta que são os camponeses que produzem alimentos no Brasil.

Mas o principal problema de tal interpretação não é apenas o jogo de palavras e a prestidigitação que visa confundir o interlocutor, o principal é que a questão que está sendo colocada é uma questão secundária. Qual a importância se é produzido por A ou por B, se você não entendeu o complexo como um todo que diferença tem se o frango é produzido por agricultor familiar pelo agronegócio se quem vai comercializar esse frango é BRF? Se quem vai vender esse frango para a população é o Carrefour, o BIG, o Walmart, o Extra?

${ }^{10}$ Disponível em http://escolamiltonsantosdeagroecologia.blogspot.com. br/2013/10/agricultura-camponesa-x-agronegocio.html

${ }^{11}$ Essa separação foi questionada por vários autores, mas destacamos Navarro (2010) que mostra o equívoco em se fazer tal separação baseado em um conceito de agricultura familiar que é pouco preciso e não mostra as reais diferenças entre os produtores rurais do Brasil. Também foi questionado pela Confederação Nacional da Agricultura que junto com a Fundação Getúlio Vargas publicaram um documento mostrando que utilizando-se o conceito de Agricultura Familiar definido pelo PRONAF a realidade apresentada era bastante diferente do que a mostrada pela publicação do MDA. Para maiores detalhes ver o documento da FGV/IBRE (2010) GV/CNA. 
SAMPAIO, F. dos S. Questão Agrária e Projeto Nacional: notas para...

Ora, ao não se entender o grau de monopólio que se tem desde a produção de suplementos para esse frango, desde a produção de sementes, que é monopolizado, desde o grau de monopolização que se tem na distribuição, na industrialização, ao buscar explicações apenas "da porteira para dentro" se vai estar levantando questões que são secundárias, que são irrelevantes do ponto de vista prático ${ }^{12}$. Mesmo do ponto de vista de formulação de políticas públicas para a agricultura essa falsa dicotomia entre agronegócio e agricultura familiar acaba prejudicando a análise. Vieira Filho e Conceição (2010) são mais coerentes com a formulação de políticas públicas ao proporem uma reclassificação da propriedade agrícola com base na matriz tecnológica.

Do ponto de vista de quem quer pensar em políticas públicas cada vez que se dá mais financiamento para o pequeno produtor que está subsumido à grande empresa, na verdade se está dando dinheiro diretamente à grande empresa porque ela vai remunerar de acordo com o nível mínimo da mão-de-obra, quanto mais se garante que essa mão-de-obra se torne mais barata, mais lucro você coloca nas mãos das grandes empresas processadoras ou distribuidoras.

Há uma melhora para o agricultor que está recebendo essa política? Sem dúvida. Mas melhora também para a grande agroindústria, o pequeno agricultor continua subsumido a ela. Ora, se não se tem essa capacidade de pensar do ponto de vista mais amplo as políticas públicas que vão sendo formuladas, elas acabam não atingindo aquilo que se quer atingir.

Mas se estivermos pensando em resistência ao capitalismo, a preocupação não é a política pública e sim a estratégia de classes

12 Vários autores já chamam a atenção para as deficiências do termo agricultura familiar e sua falsa oposição ao agronegócio. Vale destacar os textos de Germer (2012) que mostra a irrelevância prática do termo em relação ao emprego, Navarro (2010) que faz uma boa discussão da origem do conceito de agricultura familiar e seus limites e Gonçalves (2004) que mostra essa falsa dicotomia como um dos "carmas" da questão agrária brasileira. 
SAMPAIO, F. dos S. Questão Agrária e Projeto Nacional: notas para...

no momento de luta de classes. Se não se tem essa clareza, nessa integração mais ampla, não se consegue elaborar uma estratégia, não se tem a capacidade de elaborar uma estratégia de luta, saber quem são os aliados em cada momento de luta.

\section{Financeirização da agricultura e mercados}

As relações de mercado, sua dinâmica, seus mecanismos que estão presentes na agricultura faz com que seja secundário olhar apenas "da porteira para dentro" porque a agricultura hoje está vinculada a sistemas de financiamento, não apenas pelos bancos oficiais, mas também por grandes empresas de sementes ou de maquinarias. Há uma mudança significativa de 2003 para frente com o governo Lula e depois no governo Dilma que um aumento substancial do dinheiro disponibilizado pelo PRONAF, do dinheiro voltado para a agricultura familiar, ou como seria mais correto dizer, para o pequeno agronegócio, o que possibilita uma considerável melhoria no nível de vida desses agricultores.

Mas é necessário analisar também os demais determinantes como a produção de sementes, a comercialização, a integração com sistemas agroindustriais e a integração com o mercado internacional, hoje não é mais a produção que determina o preço, o preço está dado antes mesmo da produção. As bolsas de mercadorias ${ }^{13}$ que nos anos 1990 vão se fundindo e vão se transformando em poucas bolsas de mercadorias no mundo, determinam o preço de uma commodity antes dela ser produzida. E ela vai ser produzida ou não de acordo com o preço internacional. Então se muda o que era uma lógica de 30, 40 anos atrás quando o produtor produzia de acordo com o preço que ainda não estava dado, agora o preço é dado antes de que se produza. Ele não vai mais olhar qual foi o preço da saca de soja no ano passado para produzir agora pois ele já tem o preço de quanto vai ser a saca de soja daqui a 2, 3 anos.

${ }^{13}$ Uma análise mais detalhada do papel das bolsas de mercadorias no mundo está em Medeiros (2009). 
SAMPAIO, F. dos S. Questão Agrária e Projeto Nacional: notas para...

A ideia da relação entre produção, consumo, distribuição e circulação é uma matriz explicativa do marxismo e foi em grande parte abandonada, ela deve ser retomada para que se possa fazer uma análise mais ampla da agricultura. Essa análise precisa incluir a indústria de bens de capital na agricultura, a agropecuária, a agroindústria de processamento, serviços de preparação e logística, os agro serviços de aprimoramento e ampliação de negócios e os agro serviços transnacionais de distribuição. São todos setores que vão estar integrados à agricultura ${ }^{14}$, a uma agricultura moderna inserida na lógica capitalista na qual se tem um importante papel dos mercados interno e externo e das bolsas de mercadorias.

Então, a propriedade da terra, hoje não é tão importante quanto a propriedade do capital, a agricultura inserida na lógica de acumulação de capital, faz com que não se possa olhar apenas para a agricultura da "porteira para dentro", porque o que dá dinâmica para o setor está da "porteira para fora" e assim temos que levar em consideração as bolsas de mercadorias e a dinâmica dos mercados interno e externo e também as questões geopolíticas.

As questões geopolíticas são fundamentais para entender a lógica da inserção da agricultura nas estratégias de poder dos Estados nacionais. A produção de alimentos está diretamente vinculada à soberania e segurança alimentar e isso está relacionado ao jogo de poder em todo o globo, à ação das grandes empresas alimentares, às estratégias dos países ou bloco de países. Torna-se fundamental não apenas se ter condições de produzir, mas produzir, distribuir e ser soberano em ralação a isso.

Lembramos o exemplo dado no livro "Agroindústria nas Américas" de Burbach e Flynn" ${ }^{15}$, que mostra quando os EUA utilizou o seu "arsenal dos cerais" para desestabilizar economias como a da União Soviética e a do Chile, como que ele utilizou as ajudas alimentares para fazer com que suas multinacionais do setor de alimentos entrem em determinados países e passam a controlar

${ }^{14}$ Uma exposição mais detalhada encontra-se em Gonçalves, (2005).

${ }^{15}$ Ver Burbach e Flynn (1984) 
SAMPAIO, F. dos S. Questão Agrária e Projeto Nacional: notas para...

boa parte do processamento agroindustrial, isso associado aos interesses do Departamento de Estado. Fica claro que não é apenas uma questão econômica, de estratégias empresariais, mas fundamentalmente uma questão geopolítica, das mais importantes.

\section{A dicotomia agricultura familiar e agronegócio}

Uma das principais características no debate da agricultura na Geografia Agrária tem sido a falsa dicotomia entre agronegócio e agricultura familiar, como se elas fossem formas opostas de inserção da agricultura no capitalismo, em um caso o agronegócio representando o capitalismo e no outro a agricultura familiar, representando a "vida", a resistência ao capitalismo. Na verdade o que se tem são duas formas de inserção ao mercado, em ambos os casos se fala em negócios da agricultura, portanto "agro negócios". O que se apresenta são especificidades nesses agronegócios, de um lado há uma agricultura com ganhos de escala, como a produção de fibras e grãos, que quanto maior a produtividade, quanto maior a área que se produz, maior é o ganho de escala e de outro uma produção altamente especializada e diversificada que não necessita de grandes áreas de plantio, mas sim de um sistema de processamento e logística ${ }^{16}$.

Por exemplo, não se precisa ter 20 mil hectares plantados com morango, não se consegue trabalhar com esse tamanho de propriedade para esse produto, se consegue fazer algo melhor numa pequena propriedade. Também há o exemplo do leite, no qual uma propriedade de grande escala se tem deseconomias de escala, então a produção se dá em pequenas propriedades, o que não significa que será uma pequena produção, se pode ter uma propriedade pequena com uma produção grande. A produção de

${ }^{16}$ José Sidney Gonçalves (2004) chama essas duas inserções da agricultura de Modelo Texano (grandes propriedades de grão e fibras) e Modelo Californiano (pequenas áreas altamente diferenciadas e diversificadas). 
SAMPAIO, F. dos S. Questão Agrária e Projeto Nacional: notas para...

aves é um outro bom exemplo, com menos de 5 ha pode-se ter uma altíssima produção de frangos ou perus.

A agricultura em geral é um negócio, seja em pequena propriedade ou grande propriedade, mas ela é um negócio inserido ao mercado, compra insumos modernos, consome tecnologia moderna, vende para os sistemas agroindustriais, está altamente inserida no mercado. Sem dúvida ainda há os casos de agricultura de subsistência, de agriculturas rudimentares em várias partes do país, mas para esses casos é necessário considerar suas especificidades e buscar políticas públicas (ou estratégias de luta) específicas para seus casos. Colocá-las todas no grande bolo dos "agricultores familiares" e considerar que seus interesses são os mesmos que os produtores altamente inseridos no mercado é um erro que provoca equívocos estratégicos.

Quando a preocupação básica é a da geração de renda para o pequeno, numa ótica de melhoria das condições de vida do agricultor sobre o capitalismo, faz sentido haver políticas públicas para aqueles que tem menor grau de inserção aos mercados, elevar o seu grau tecnológico, garantir preços, financiar as cadeias de processamento e logística, ou seja, criar políticas públicas voltadas à sua especificidade enquanto um negócio (ou agronegócio) de pequena escala. No entanto, não é possível considerar que tais políticas sejam formas de resistência ao capitalismo, que sejam ações para impedir o avanço do capitalismo, segurando o homem no campo.

\section{Considerações finais}

Qualquer discussão ligada ao rural brasileiro deve estar associado a aspectos mais amplos da realidade do desenvolvimento do capitalismo e industrialização da agricultura. A discussão da geografia agrária deve contemplar os estudos dos sistemas agroalimentares englobando agricultura, indústria e serviços, englobando todo o sistema de agroindústria de processamento, produção de insumos e agrosserviços. 
SAMPAIO, F. dos S. Questão Agrária e Projeto Nacional: notas para...

Assim propõe-se voltar à ideia da totalidade, das relações inter e intrasetoriais, das relações do global com o local no qual a Geografia nos proporciona excelentes ferramentas. Ao se analisar nessa perspectiva percebe-se que o fundamental não são apenas as políticas públicas voltadas a casos específicos, mas também em numa ideia mais ampla, a de um projeto nacional. Tendo em vista um projeto nacional deve-se pensar qual o papel da agricultura em sua concepção mais ampla, quais as formas de alavancar a produção agroalimentar tanto para o mercado interno quanto ao externo, de verificar as especificidades da agricultura diversificada de pequena escala (a assim chamada "agricultura familiar") e da agricultura padronizada de grande escala (o chamado agronegócio).

Um projeto nacional deve ser motivado pela volta do crescimento econômico. Para Inacio Rangel isso se daria pelo uso da capacidade ociosa, o uso do latifúndio improdutivo entra nessa lógica de utilização de capacidade ociosa, para produzir alimentos e para produzir matérias-primas. A agricultura tem uma resposta mais rápida do que em outros setores ${ }^{17}$, daí a nossa saída da crise nos anos 2000 estar associada à capacidade ociosa da agricultura.

$\mathrm{O}$ aumento não só de área plantada mas também o aumento da intensidade de tecnologia utilizada na agricultura tem que ser pensada como forma de sair da crise. Os problemas dos nós de estrangulamentos, por exemplo, as infraestruturas, a falta de estradas, de portos, de ferrovias, isso também é um problema da agricultura não é apenas um problema "de logística". Não é possível entender a agricultura, distribuição de alimentos, barateamento para a população trabalhadora da cidade sem atacar diretamente esses problemas das infraestruturas.

Um dos grandes problemas de acesso à alimentação não se dá pela falta da produção, mas pela falta de renda ou de mecanismos de distribuição, assim é necessário criar políticas de emprego, de distribuição de renda e garantir infraestruturas que possibilitem os alimentos chegarem à mesa dos trabalhadores.

${ }^{17}$ Essa ideia é apresentada por Medeiros (2009). 
SAMPAIO, F. dos S. Questão Agrária e Projeto Nacional: notas para...

Pensar um projeto nacional significa entender todas essas especificidades colocar como bandeira de luta o crescimento econômico, a geração de empregos e a melhoria da condição de vida dos trabalhadores em geral e não apenas a sobrevivência da tradição, da família e da propriedade dos pequenos agricultores.

\section{Referências bibliográficas}

BATCHIKOV, Serguei; GLASEV, Serguei y KARA-MURZA, Serguei. El libro blanco de Rusia: las reformas neoliberales (1991-2004). Madrid: El Viejo Topo, 2007.

BROIETTI, Marcos Henrique. Os boias-frias no Paraná: Entre a Aparência e a Essência. Tese (Doutorado em Geografia). Universidade Federal de Santa Catarina. Florianópolis, 2004.

BUAINAIN, Antônio Marcos et all. Sete teses sobre o mundo rural brasileiro. Revista de Política Agrícola. Brasília, Ano XXII, n. 2, 2013. Pp. 105-121.

BURBACH, Roger, FLYNN, Patrícia. Agroindústria nas Américas. Rio de Janeiro: Zahar, 1982.

FGV/IBRE. Quem produz o que no campo: quando e onde II. Censo agropecuário 2006: resultados: Brasil e regiões. Brasília: Confederação da Agricultura e Pecuária no Brasil, 2010.

GERMER, Claus Magno. Marx e o papel determinante das forças produtivas na evolução social. Crítica Marxista, n. 29, São Paulo: Ed. Unesp, 2009. pp75-95.

GERMER, Claus Magno. A irrelevância prática da agricultura "familiar" para o emprego agrícola. Geografia econômica: anais de geografia econômica e social. N. 4, Florianópolis: UFSC, 2012. Pp. 109-132.

GONÇALVES, José Sidney. Agricultura sob a égide do capital financeiro: passo rumo ao aprofundamento do desenvolvimento 
SAMPAIO, F. dos S. Questão Agrária e Projeto Nacional: notas para...

dos agronegócios. Informações Econômicas, SP, v.35, n.4, abr. 2005. pp. 07-35.

GONÇALVES, José Sidney. Carmas da questão agrária. Informações Econômicas, SP, v.34, n.7, jul. 2004. pp.41-44.

GONÇALVES, José Sidney. Fim do Alimento Barato: ressurreição do fantasma malthusiano ou manifestação do mito do desenvolvimento econômico. Informações Econômicas, SP, v. 42, n.2, mar/abr. 2012. pp. 83-95.

MAMIGONIAN, Armen. Estudos de Geografia Econômica e de Pensamento Geográfico. Livre Docência: FFLCH-USP, 2005.

MARX, K e ENGELS, F. Manifesto do Partido Comunista. In Textos. Vol. 3. São Paulo: Edições Sociais, 1975. pp. 13-47.

MEDEIROS, Marlon Clovis. A Geografia Econômica do Setor Agroalimentar Brasileiro: investimentos, recursos ociosos e dinâmica cíclica (1990-2007). Tese (Doutoramento em Geografia). Universidade de São Paulo. São Paulo, 2009.

NAVARRO, Z. Agricultura Familiar no Brasil: entre a política e as transformações da vida econômica. In A Agricultura Brasileira. Brasília: IPEA, 2010. pp.185-209.

VIEIRA FILHO, José Eustáquio Ribeiro e CONCEIÇÃO, Júnia Cristina Peres. Censo Agropecuário 2006: uma crítica ao recorte metodológico. Brasília: Ipea, 2010 (Radar, n. 6).

WOLF, Eric. R. Guerras camponesas do século XX. São Paulo: Global, 1984.

Recebido em

Aceito em 